\title{
Role of miR-34 in gastric cancer: From bench to bedside (Review)
}

\author{
SHENGWEI XIONG ${ }^{1 *}$, MINGLI HU ${ }^{1 *}, \mathrm{CHENYU} \mathrm{LI}^{1}, \mathrm{XIAODONG} \mathrm{ZHOU}^{1}$ and HONGXIA CHEN ${ }^{2}$ \\ Departments of ${ }^{1}$ Gastroenterology, ${ }^{2}$ Obstetrics and Gynecology, First Affiliated Hospital \\ of Nanchang University, Nanchang, Jiangxi 330006, P.R. China
}

Received January 27, 2019; Accepted April 8, 2019

DOI: $10.3892 /$ or.2019.7280

\begin{abstract}
Gastric cancer (GC) is a prevalent digestive system malignancy that is associated with a poor prognosis specifically for advanced-stage patients. MicroRNAs (miRNAs) are small, non-coding RNAs that have been reported to play roles as oncogenes or tumour suppressors in all types of cancer, including GC, by post-transcriptionally regulating cancer-related genes. Recently, miR-34a and miR-34b/c, members of the microRNA-34 (miR-34) family, were identified to be direct transcriptional targets of the onco-suppressor p53. In this review, we report that miR-34 is epigenetically downregulated or silenced in GC tissues and cell lines, changes which may result from mutations in p53 or DNA methylation and histone modifications of the miR-34 promoter regions. Moreover, miR-34 has been identified as a tumour-suppressor in GC. p53-induced miR-34 regulates several different target genes and signalling pathways, inducing apoptosis, senescence, and cell cycle arrest and repressing GC cell proliferation, migration and metastasis, thus contributing to the suppression of carcinogenesis and GC cancer progression. Furthermore, miR-34 is a novel prognostic and predictive biomarker in GC, and restoring miR-34 expression by delivering miR-34 mimics may be a promising therapeutic strategy for the treatment of GC.
\end{abstract}

\section{Contents}

1. Introduction

2. Biogenesis and structure of the miR-34 family

Correspondence to: $\mathrm{Dr}$ Xiaodong Zhou, Department of Gastroenterology, First Affiliated Hospital of Nanchang University, 17 Yongwaizheng Street, Donghu District, Nanchang, Jiangxi 330006, P.R. China

E-mail: yfyzxd@163.com

Dr Hongxia Chen, Department of Obstetrics and Gynecology, First Affiliated Hospital of Nanchang University, 17 Yongwaizheng Street, Donghu District, Nanchang, Jiangxi 330006, P.R. China

E-mail: yfychx@163.com

*Contributed equally

Key words: microRNA-34, gastric cancer, regulatory mechanisms, biomarker, therapeutic application
3. miR-34 joins the $p 53$ tumour-suppressor network

4. Function of miR-34 and its target genes in gastric cancer

5. Expression of miR-34 in gastric cancer

6. Signalling pathways modulated by miR-34 in gastric cancer

7. Clinical implications of miR-34

8. Conclusion

\section{Introduction}

Gastric cancer (GC) is the fourth most common malignancy in humans and the second leading cause of cancer-related death worldwide, with approximately one million new cases each year (1). Chronic infection with Helicobacter pylori is a major risk factor for the initiation and progression of $\mathrm{GC}$, with approximately $90 \%$ of non-cardia GC attributed to infection with this bacterium $(2,3)$. At present, early diagnosis of GC patients is extremely difficult, and the prognosis for advanced-stage patients remains extremely poor, with a 5-year survival rate of only $\sim 24 \%$ (2). Thus, the identification of novel biomarkers and an improved understanding of the mechanisms underlying $\mathrm{GC}$ carcinogenesis, progression, and metastasis are of utmost importance.

MicroRNAs (miRNAs) are endogenous RNAs with a length of $\sim 22$ nucleotides, which are key post-transcriptional regulators of gene expression (4). In general, these small non-coding RNAs bind to 3'-untranslated regions (UTRs) on their target messenger RNAs (mRNAs), typically resulting in repressed gene expression (5). Increasing evidence indicates that miRNAs are involved in many crucial biological processes, including cell proliferation, invasion, migration, differentiation, and apoptosis, as well as tumour metastasis and angiogenesis $(4,5)$. In addition, miRNAs are known to play significant roles in all types of cancers, including GC, and they also function as oncogenes or tumour suppressors by post-transcriptionally regulating cancer-related genes (6). Recently, microRNA-34 (miR-34) family members, including miR-34a and miR-34b/c, have been identified as direct transcriptional targets of the onco-suppressor $p 53$, the expression levels of which are significantly influenced by DNA damage and oncogenic stress (7). In various human cancers, including $\mathrm{GC}$, the expression of miR-34 family members is epigenetically silenced. Moreover, $p 53$-induced miR-34 promotes cell apoptosis and senescence, induces cell cycle arrest, represses cancer cell invasion and metastasis, and inhibits epithelial-mesenchymal transition to inhibit carcinogenesis and 
cancer development (4). Successful cancer treatments should not only be aimed at targeting proliferating cancer cells but also resting cancer stem cells (CSCs) $(8,9)$. Given its essential role in the self-renewal and differentiation of CSCs, miR-34a may represent a promising therapeutic target against CSCs in GC (10). Here, we review the biogenesis and epigenetic dysregulation of miR-34 in human GC, and summarize verified miR-34 target genes in GC. This review also discusses the potential clinical value of miR-34 as a novel prognostic and predictive biomarker, as well as its potential use as a therapeutic target for the treatment of GC.

\section{Biogenesis and structure of the miR-34 family}

The miR-34 family consists of three homologous miRNAs (miR-34a and miR-34b/c) that are encoded by two distinct genomic loci located on chromosomes $1 \mathrm{p} 36$ and 11q23, respectively (Fig. 1) (11-13). First, miR-34 genes are transcribed as primary transcripts (pri-miR-34) from the transcription start site in the nucleus by RNA polymerase II/III. Next, the pri-miR-34 is polyadenylated and capped with 7-methylguanosine. The pri-miR-34 is then cleaved into precursor miR-34 (pre-miR-34) by DGCR8 (DiGeorge syndrome critical region gene 8), and the pre-miR-34 is finally transported to the cytoplasm to create a miR-34 duplex, which contains the mature miR-34 mediating post-transcriptional gene silencing by partially binding to the 3'-UTR of target message RNAs (14).

Animal studies have demonstrated that miR-34a is ubiquitously expressed and that the highest levels are found in the brain, whereas the highest levels of miR-34b/c expression are found in the lungs, with lower levels in the brain and testis (7). Expression of miR-34b/c in other tissues is scarce or undetectable (7). miR-34c is also abundantly expressed in human sperm and testis, but it is absent in human ovaries (15). Thus, these findings suggest that these three miR-34 isoforms may have tissue-specific functions. Interestingly, miR-34a and miR-34c have identical seed sequences (nucleotides 2-7 from the 5'-UTR), whereas the miR-34b seed sequence is similar, but not identical (Table I) (16), indicating that miR-34a and miR-34c may share similar mRNA targets. miR-34 isoforms use their seed sequences to recognize the 3'-UTRs of their target mRNAs by incomplete base pairing, inducing mRNA destabilization or translational repression of target genes.

\section{3. miR-34 joins the p53 tumour-suppressor network}

p53, which serves as a tumour-suppressor gene, has been implicated in many malignancies in humans $(17,18)$. In 2007 , several studies have identified miR-34a and miR-34b/c as direct $p 53$ target genes that regulate cell proliferation and induce apoptosis $(7,13,19,20)$. Upstream regions of miR-34 family genes house one or more predicted $p 53$ binding sites, and $p 53$ directly binds to those response elements, transactivating the expression of miR-34 $(7,13)$. Yamakuchi et al demonstrated that restoration of miR-34a decreased the level of silent information regulator 1 (SIRT1) that inactivates $p 53$ by deacetylation, leading to an increase in acetylated $p 53$ levels and expression of $p 21$ and PUMA, which are post-transcriptional targets of $p 53$ that regulate the cell cycle and apoptosis, respectively (21). Additionally, other studies have described a positive feedback loop between $p 53$ and miR-34a, such as a miR-34a/MDM4/p53 loop and a miR-34a/MYC/p53 loop, in which $p 53$ activates miR-34a expression and miR-34a in turn increases the activity of $p 53$, thereby inducing a series of cellular processes associated with tumour suppression and apoptosis $(22,23)$. Notably, Christoffersen et al showed that oncogene-induced senescence strongly upregulated miR-34a in a p53-independent manner, which indicates that alternative cancer-related pathways regulate miR-34a, emphasizing its significance as a tumour suppressor (24).

\section{Function of miR-34 and its target genes in gastric cancer}

miR-34 has been deemed to possess tumour-suppressive properties in light of its synergistic effect with the well-known tumour suppressor $p 53$ (25). In previous studies, it has been reported that restoration of miR-34a expression induces pro-apoptotic functions in various cancer cell lines, whereas inactivation of endogenous miR-34a protects wild-type p53-expressing cells from DNA damage-induced cell death $(20,26,27)$. Ectopic expression of miR-34 has also been shown to induce cell cycle arrest in various cancer cell lines by suppressing cyclins D1 and E2, cyclin-dependent kinase 4 (CDK4) and CDK6 $(13,28)$. Indeed, miR-34 has been shown to promote the processes that inhibit carcinogenesis, such as apoptosis and senescence, and to inhibit cancer progression via cell cycle arrest and suppression of proliferation, invasion and metastasis (26-29).

miR-34 is recognized as a tumour suppressor, and generalized silencing of miR-34 results in abnormally high expression of oncogenic targets in tumours $(30,31)$. Consequently, miR-34 target genes have commonly been found to be overexpressed in GC. By microarray analysis, Zhou et al identified IGF2BP3, a target of miR-34a, as the highest upregulated gene in nine GC cell lines (32).Notably, some distinctions exist with regard to their respective target genes: miR-34b targets Notch2 and Notch4, whereas miR-34c targets Notch1-4 $(10,33)$.

As a vital component of the $p 53$ suppressor network, miR-34 has been well documented to regulate multiple apoptosis-related genes in GC $(34,35)$. As shown in Table II, miR-34a promotes $\mathrm{GC}$ cell apoptosis by negatively modulating survivin, Bcl-2, and Tigf2. Among these target genes, Bcl-2, along with its family members, is believed to be a central regulator of apoptosis (10). miR-34 has also been shown to be regulated by $p 53$ during the suppression of tumour cell proliferation. It has previously been reported that miR-34a negatively modulates survivin in GC cells and that survivin expression in tumours correlates with the proliferation of cancer cells (36). Although SIRT1 dysregulation by miR-34a in GC cells has been demonstrated to be responsible for inhibiting proliferation and promoting apoptosis, SIRTI has been shown to act as a tumour suppressor in intestinal carcinogenesis (37).

The miR-34a/CD44 axis is thought to affect the metastatic ability of GC cells by regulating the cellular cytoskeletonassociated protein Ras homolog family member A (RhoA), LIM domain kinase-1 (LIMK-1), and matrix metalloproteinase (MMP)-2 (38). Interestingly, it has been shown that simultaneous overexpression of $M E T$ and $P D G F R$ results in a stronger inhibitory effect of the suppressive action of miR-34a on GC cell migration, invasion, and proliferation than when 


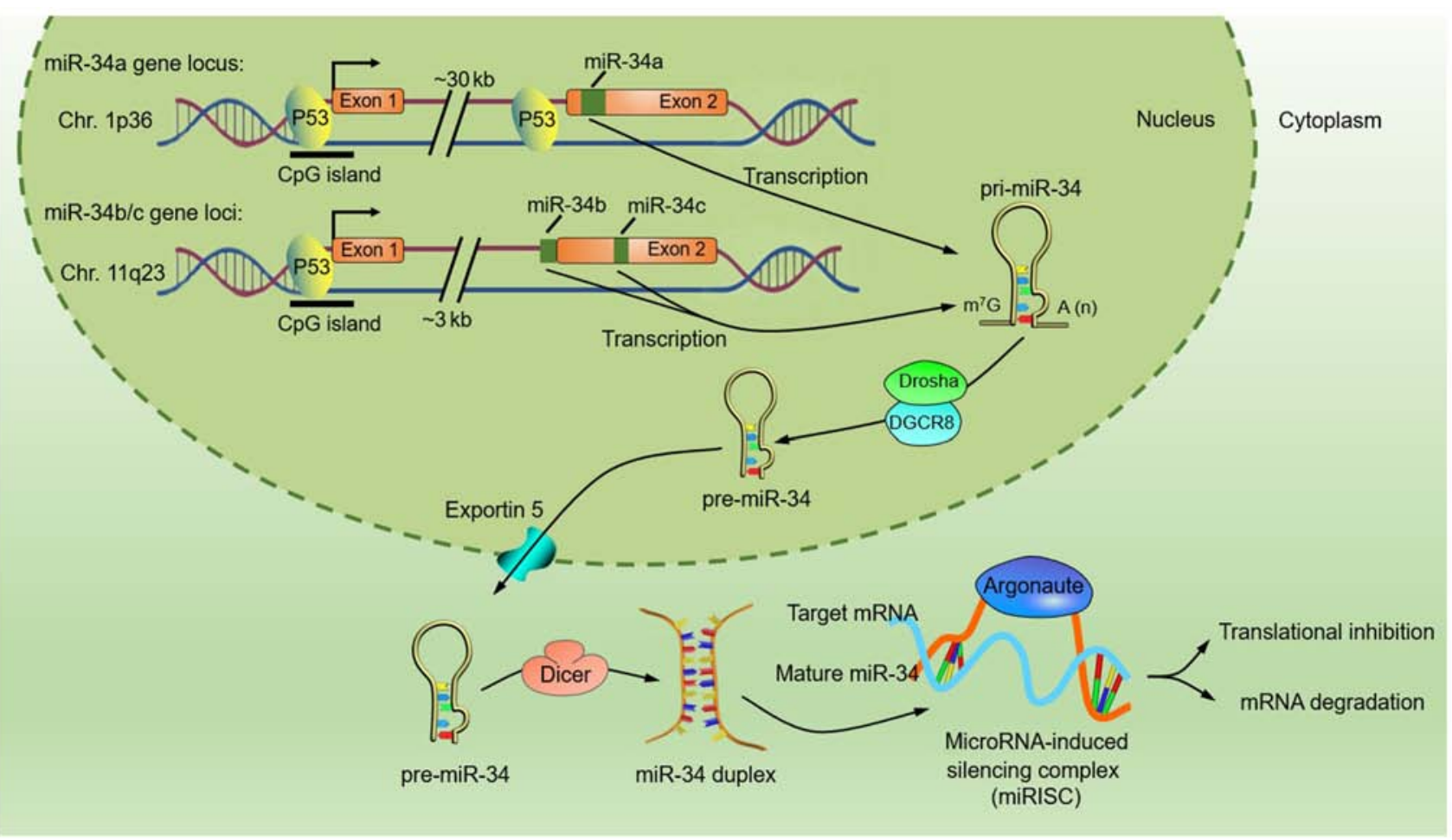

Figure 1. Structure and biogenesis of the miR-34 family. miR-34a is encoded by an individual transcript, and the gene is located at the chromosome $1 \mathrm{p} 36$ locus (11). In contrast, miR-34b and miR-34c share a common host gene located on chromosome 11q23 (12). The mature miR-34a sequence is located within the second exon of its host gene, approximately $30 \mathrm{~kb}$ downstream of the first exon, and the proximal region of the first exon houses a predicted $p 53$ binding site. miR-34b- and miR-34c-encoding sequences are located within intron 1 and exon 2, respectively, of the same precursor (miR-34b/c), and the proximal regions of their transcriptional start site houses a consensus $p 53$-binding site $(7,13)$. These $p 53$-binding sites are evolutionarily conserved and consistent with the general characteristics of $p 53$-regulated protein-coding targets. First, the miR-34 gene is transcribed by RNA polymerase II/III, thereby generating a primary miR-34 (pri-miR-34) that then undergoes nuclear cleavage to form precursor miR-34 (pre-miR-34) by the microprocessor complex of Drosha and DGCR8. Finally, pre-miR-34 is cleaved by RNase Dicer in the cytoplasm to create a miR-34 duplex, which contains the mature miR-34 that assembles into the miRNA-induced silencing complex (miRISC) with Argonaute, while the other is supposedly degraded.

either target is overexpressed alone (39). Moreover, $C D 44$ is a significant marker of cancer stem cells (CSCs), including gastric CSCs (40). In recent years, the ability of tumour sphere formation of GC cells, which generally represents the self-renewal and differentiation potential of CSC, has been documented to be correlated with miR-34a-mediated suppression through direct modulation of the downstream targets CD44, Bcl-2, Notch, HMGA2, Nanog, Oct4, SOX-2 and YY1 (16,33). Although most information concerning the role of miRNA-34a in CSC generation or differentiation has been obtained only from studies in cell culture models, miR-34a may also represent a promising therapeutic target against CSCs in GC.

Almost all the published reports have confirmed a tumoursuppressive function of miR-34a in GC. However, there are some reports that demonstrated an adverse function of miR-34a in other cancers. $\mathrm{Pu}$ et al reported that transfection with the miR-34a mimic made osteosarcoma G-292 cells multi-chemoresistant, with resistance against cisplatin increasing 1.66-fold, mainly through the downregulation of the Delta like ligand 1 (DLL1) gene, the ligand of the Notch pathway (41). Moreover, Krause et al demonstrated an oncogenic role for miR-34a as it promoted genomic instability, tumourigenesis and tumour progression by regulating the Kaposi's sarcoma-associated herpesvirus (KSHV)-encoded chemokine receptor $v G P C R$ (42). Additionally, in an early study, the authors reported that the knockdown of miRNA-34a with siRNA significantly inhibited the proliferation of renal carcinoma, HeLa and MCF7 cells, which indicated that the overexpression of miR-34a may be an acquired trait during carcinogenesis but warrants further investigation (43). In a word, to clarify the tumour-suppressive and oncogenic roles in versatile cancers requires more mechanistic and detailed studies.

\section{Expression of miR-34 in gastric cancer}

Aberrant expression of miR-34. Since the first report of loss of expression in glioblastoma (11), miR-34a and miR-34b/c have been found to be aberrantly expressed in various human cancers, including GC (56). Indeed, miR-34 has been shown to be downregulated in most GC tissues compared with normal mucosa (Table III). Hui et al evaluated the expression of miR-34a in $76 \mathrm{GC}$ tissues and corresponding adjacent normal tissues by quantitative real-time polymerase chain reaction (qPCR), and they showed that miR-34a expression was decreased in GC tissues and that downregulation of miR-34a expression correlated significantly with the Lauren classification of GC (57). In addition, Kim et al analysed 90 GC tissues and 34 normal samples and identified a miRNA profile signature distinguishing GC from normal stomach epithelium, indicating that the expression of miR-34b in GC tissue was downregulated to 0.64 compared with normal tissue (58). 
Table I. Sequences of the human miR-34 family members.

\begin{tabular}{lll}
\hline miR-34 isoforms & \multicolumn{1}{c}{ Previous IDs } & \multicolumn{1}{c}{ Sequence (5' $3^{\prime}$ ) } \\
\hline hsa-miR-34a-5p & hsa-miR-34a & 22-UGGCAGUGUCUUAGCUGGUUGU-43 \\
hsa-miR-34a-3p & hsa-miR-34a* & 64-CAAUCAGCAAGUAUACUGCCCU-85 \\
hsa-miR-34b-5p & hsa-miR-34b; hsa-miR-34b* & 13-UAGGCAGUGUCAUUAGCUGAUUG-35 \\
hsa-miR-34b-3p & hsa-miR-34b & 50-CAAUCACUAACUCCACUGCCAU-71 \\
hsa-miR-34c-5p & hsa-miR-34c & 13-AGGCAGUGUAGUUAGCUGAUUGC-35 \\
hsa-miR-34c-3p & - & 46-AAUCACUAACCACACGGCCAGG-67
\end{tabular}

miR-34-5p is the traditional mature miR-34 that assembles into RNA-induced silencing complex (RISC), and its complementary strand miR-34-3p is supposedly degraded. The seed sequences on 5'-UTRs (underlined) combine with targeted mRNAs for regulatory purposes. These data were collected from miRbase (www.mirbase.org) (modified from ref. 16).

Likewise, Wang et al demonstrated that the expression of miR-34a and miR-34c, but not miR-34b, was lower in GC than that in adjacent normal tissue (33).

In human GC cell lines, expression of the miR-34 family has been extensively investigated (Table IV). For example, by qPCR, Hui et al discovered that a panel of GC cell lines, such as NCI-N87, AGS, MKN-45, MKN-28, BGC-823 and SGC7901, all expressed significantly lower levels of miR-34a than the immortalized normal human gastric epithelial cell line GES-1, indicating that decreased miR-34a expression may be related to GC oncogenesis (57). In addition, Suzuki et al found that $\mathrm{miR}-34 \mathrm{~b} / \mathrm{c}$ expression was downregulated in a larger panel of GC cell lines (59).

Of note, miR-34 expression was also explored using the TCGA (The Cancer Genome Atlas) database in previous studies. For example, Wei et al investigated miR-34a expression in an independent cohort ( $\mathrm{n}=352 \mathrm{GC}$ specimens) from the TCGA database (50). The results revealed lower levels of miR-34a expression in GC tissues and significantly lower levels of miR-34a expression in T3 and T4 tumour stages compared with $\mathrm{T} 1$, and low levels of miR-34a predicted longer survival rates in patients with GC (50).

However, as shown in Table III, miR-34a and miR-34b/c were upregulated in GC tissues in all three studies conducted in Japan and some conducted in China. The lack of agreement between different studies with respect to miR-34 expression can be explained by a variety of factors, some of which are discussed below. First, different studies used different reagents and analytical approaches. Second, the inclusion of a small number of cancer samples may affect the reliability of the miR-34 expression level measurements. Moreover, studies reporting upregulated expression of miR-34 generally profiled a large number of miRNAs in human GC tissues, an approach that may lack sensitivity, specificity and reliability. Significantly, miR-34 expression levels in GC tissues obtained from GC patients without distant metastases, as opposed to those obtained from patients with higher clinical TNM stages and with poor tumour differentiation, were demonstrated to be different. In addition, prior administration of any type of targeted therapy, radiotherapy, chemotherapy, and/or intervention for GC may also affect miR-34 expression levels in GC tissues. Moreover, living conditions (rural or urban), social status, and lifestyle behaviour, such as cigarette smoking and alcohol consumption, are also associated with miR-34 expression patterns in GC (60). The inconsistency in the methods employed in the mentioned reports requires additional analyses to draw a reliable conclusion that is applicable for cancer diagnosis and treatment.

Mechanisms of miR-34 inactivation. In previous studies, the expression of miR-34a and miR-34b/c was commonly lost or downregulated in many types of cancerous tissues and cancer cell lines, including GC. However, the correlation of downregulated miR-34 with GC and its precise role during carcinogenesis and cancer progression are still unclear. Therefore, identifying the underlying mechanisms involved in the downregulated expression of miR-34 is of the utmost importance.

As miR-34 is directly transactivated by tumour suppressor $p 53$, missense mutations in the $p 53$ gene and genomic alterations of the $p 53$ binding site may result in the downregulation of miR-34 expression (70). In this regard, Hanazono et al reported that a $p 53$ gene mutation was present in approximately $50 \%$ of GC patients and that expression of wild-type $p 53$ protein becomes undetectable in GC tissues as it is replaced by overexpression of mutant forms (71). In addition, Ji et al demonstrated the lowest level of miR-34a expression in Kato III (a GC cell line), which is generally considered to carry a mutant form of $p 53$ (10). Moreover, Corney et al demonstrated a reduction of miR-34a expression in human epithelial ovarian cancer (EOC) tissues with both wild- or mutant-type $p 53$ (decreased by 93 and 100\%, respectively), and of miR-34b/c expression in $72 \%$ of EOC tissues bearing a $p 53$ mutation (72).

Several studies have shown that silencing of miR-34a and $\mathrm{miR}-34 \mathrm{~b} / \mathrm{c}$ in GC is associated with epigenetic inactivation of miR-34 genes $(70,73)$. Epigenetic modifications include DNA methylation, histone modification, and chromatin remodelling (74). In mammalian genomes, DNA methylation occurs almost exclusively on cytosine residues that precede guanine $(\mathrm{CpG})$, within clusters of $\mathrm{CpG}$ dinucleotides in guanine-cytosine-rich regions of the genome called 'CpG islands'. Approximately $60 \%$ of human genes harbour $\mathrm{CpG}$ islands in their promoter regions (74). The process of $\mathrm{CpG}$ island methylation is catalysed by DNA methyltransferases (DNMTs) (75). The proximal upstream regions of miR-34a and miR-34b/c also contain CpG islands within promoter 


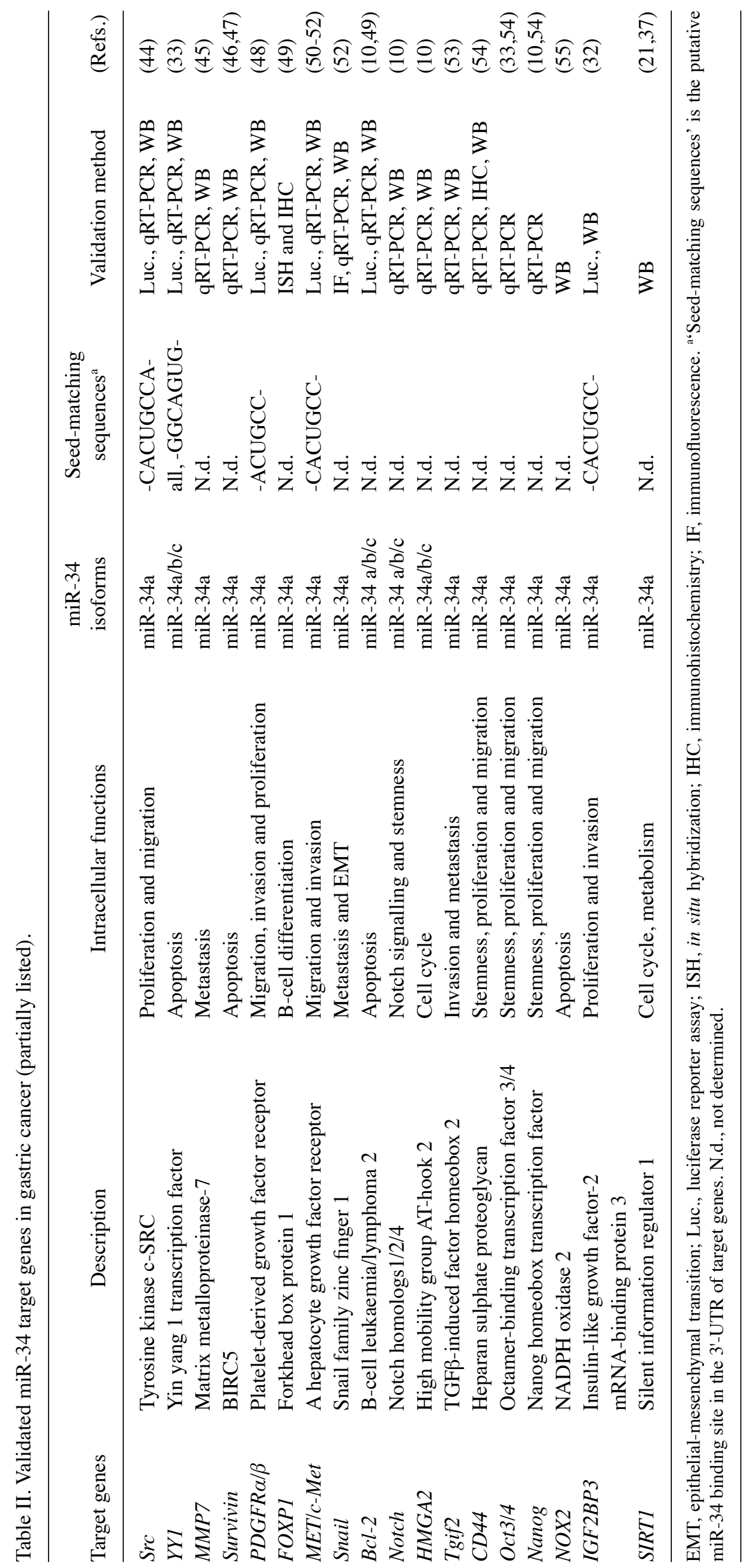


Table III. miR-34 family expression in gastric cancer tissues (partial list).

\begin{tabular}{lllllll}
\hline miRNA & Expression & $\begin{array}{c}\text { Fold change } \\
\text { (vs. normal) }\end{array}$ & $\begin{array}{c}\text { Tissue samples } \\
\text { (cancerous/normal) }\end{array}$ & $\begin{array}{c}\text { Sample } \\
\text { regions }\end{array}$ & $\begin{array}{c}\text { Validation } \\
\text { methods }\end{array}$ & (Refs.) \\
\hline miR-34b/c & Upregulated & $1.90 / 4.20$ & $17(11 / 6)$ & Japan & qRT-PCR & $(61)$ \\
miR-34a & Upregulated & $1.76-3.55$ & $20(10 / 10)$ & China & qRT-PCR & $(62)$ \\
miR-34a & Upregulated & 1.25 & $74(37 / 37)$ & Japan & Oligo chips & $(63)$ \\
miR-34a & Upregulated & - & $40(20 / 20)$ & China & qRT-PCR & $(64)$ \\
miR-34a & Upregulated & 4.03 & $27(22 / 5)$ & Japan & Microarray chips & $(65)$ \\
miR-34b & Downregulated & 0.64 & $124(90 / 34)$ & Korea & Microarray chips & $(58)$ \\
miR-34b & Downregulated & 0.583 & $144(72 / 72)$ & Taiwan, China & qRT-PCR & $(66)$ \\
miR-34a & Downregulated & $<0.5$ & $48(39 / 9)$ & Hungary & qRT-PCR & $(60)$ \\
miR-34a & Downregulated & $\sim 0.5$ & $20(10 / 10)$ & China & qRT-PCR & $(44)$ \\
miR-34a & Downregulated & - & $24(12 / 12)$ & China & qRT-PCR & $(45)$ \\
miR-34a & Downregulated & 0.299 & $6(3 / 3)$ & China & Microarray chips & $(67)$ \\
miR-34a/c & Downregulated & - & $64(32 / 32)$ & China & qRT-PCR & $(33)$ \\
miR-34a & Downregulated & - & $137($ high 64/low 73) & China & qRT-PCR & $(68)$ \\
miR-34a & Downregulated & $0.43-0.64$ & $152(76 / 76)$ & China & qRT-PCR & $(57)$ \\
miR-34a & Downregulated & $\sim 0.6$ & $40(20 / 20)$ & China & qRT-PCR & $(50)$ \\
miR-34a & Downregulated & $\sim 0.5$ & $16(8 / 8)$ & China & Microarray chips & $(69)$ \\
\hline
\end{tabular}

Table IV. miR-34 family expression in gastric cancer cell lines.

\begin{tabular}{lllll}
\hline miRNA & Expression & \multicolumn{1}{c}{ GC cell lines } & Validation methods & (Refs.) \\
\hline miR-34a & Downregulated & NCI-N87, AGS, MKN-45, MKN-28, BGC-823 and & qRT-PCR & $(57)$ \\
& & SGC-7901 & \\
miR-34a & Downregulated & AGS, BGC-823, MGC-803 and SGC-7901 & qRT-PCR & $(69)$ \\
miR-34a & Downregulated & MGC803, SGC-7901, HGC-27 and NCI-N87 & qRT-PCR & $(46)$ \\
miR-34a/b/c & Downregulated & AGS, MKN45, NCI-N87 and Kato III & TaqMan RT-PCR & $(10)$ \\
miR-34b/c & Downregulated & MKN74, SNU1, SNU638, JRST, Kato III, AZ521, & TaqMan RT-PCR & $(59)$ \\
& & MKN28, MKN45, AGS and NCI-N87 & & \\
\hline
\end{tabular}

regions, and miR-34 genes are transcribed from transcription start sites located in the CpG island (76). Recently, several studies have demonstrated that silenced expression of miR-34a and $\mathrm{miR}-34 \mathrm{~b} / \mathrm{c}$ in GC tissues and cell lines results from aberrant $\mathrm{CpG}$ island methylation in their promoter regions. Lodygin et al reported that in a broad range of cancer tissues and cell lines, miR-34a expression was silenced due to aberrant $\mathrm{CpG}$ island methylation of its promoter (73). Likewise, using methylation-specific PCR analysis, Suzuki et al confirmed that the $\mathrm{CpG}$ islands of miR-34b and miR-34c were completely methylated in most GC cell lines tested. In contrast, in normal human gastric epithelial cells, the majority of $\mathrm{CpG}$ sites were unmethylated (59). In their study, these investigators also detected elevated levels of miR-34b and miR-34c methylation in 83 of 118 (70.3\%) tumour tissues from primary GC patients by means of bisulphite-pyrosequencing. In contrast, only limited methylation $(<15.0 \%)$ was detected in normal gastric mucosa (59). Using a qPCR method, Tsai et al demonstrated that expression of miR-34b was upregulated following treatment of five GC cell lines with 5-Aza-dC (a DNA-demethylating agent) (66).
In addition to DNA methylation, histone modification is another pivotal type of epigenetic modification that correlates with the silencing of miR-34 expression in human GC. Liu et al demonstrated that HOX antisense intergenic RNA (HOTAIR) epigenetically silenced miR34a expression by binding to polycomb repressive complex 2 (PRC2) to promote the epithelial-to-mesenchymal transition in human GC (52). PRC2 represses miR-34a gene transcription by trimethylating histone $\mathrm{H} 3$ lysine 27 (H3K27me3) in its promoter region (52). Likewise, Zhang et al demonstrated that SIRT7, a NAD ${ }^{+}$-dependent acetylated lysine 18 of histone $\mathrm{H} 3$ (H3K18Ac) deacetylase that is overexpressed in human GC, promoted GC growth and inhibited apoptosis of GC cells. It was found that SIRT7 selectively bound to promoter regions of miR-34a and deacetylated H3K18ac, resulting in decreased miR-34a expression (77). Moreover, Lin et al showed that depletion of HDAC1, a histone deacetylase (HDAC), in GC cells by transfection with a specific knockdown siRNA, resulted in a nearly 4-fold upregulated expression level of miR-34a (38). Moreover, alteration of the miR-34 biogenesis machinery may also cause aberrant miR-34 expression. Based 
A
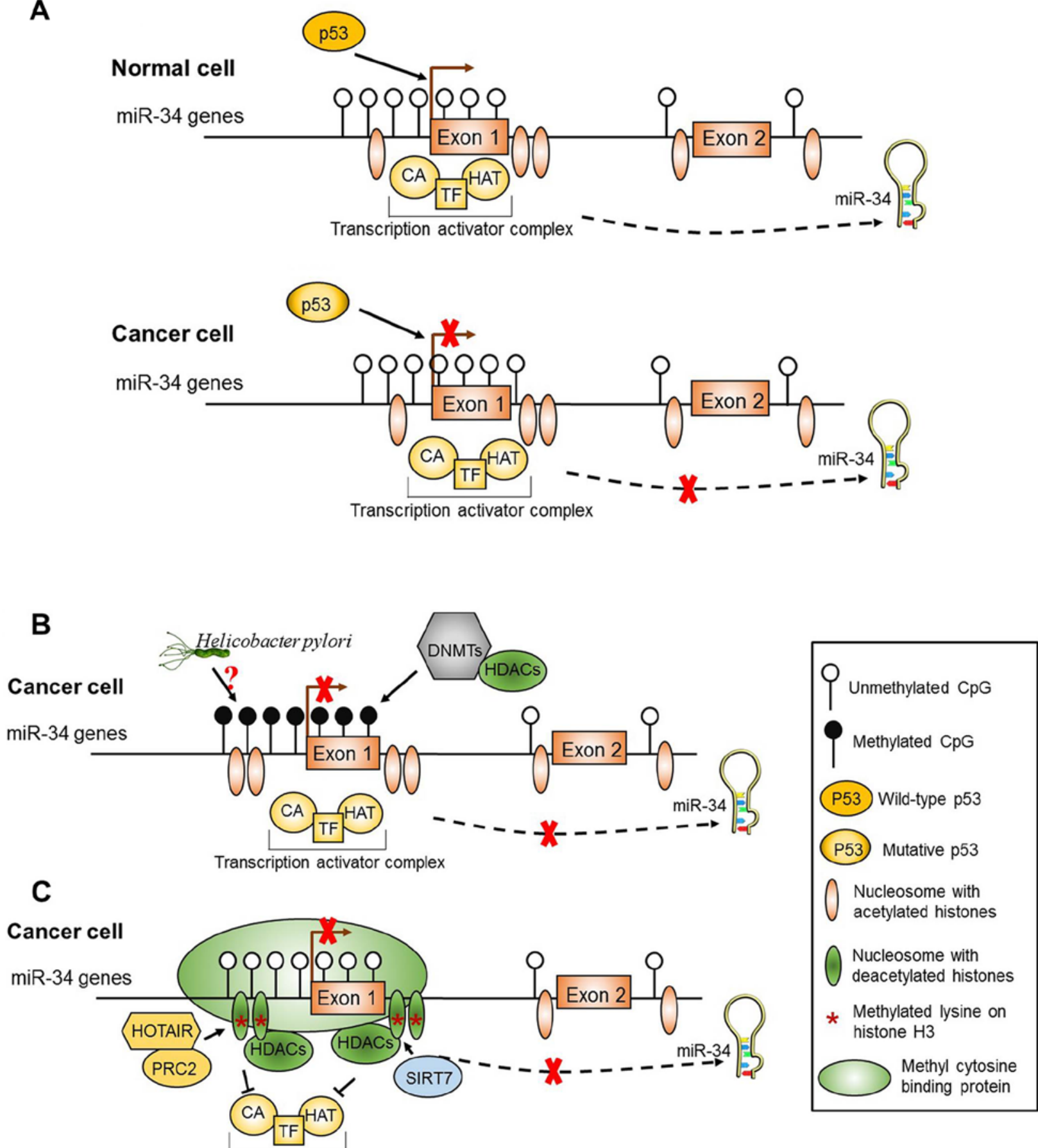

Transcription activator complex

Figure 2. Schematic diagram of the putative regulatory mechanisms of miR-34 expression in normal cells and gastric cancer (GC) cells. (A) The regulation of miR-34 expression by $p 53$. In normal cells, once activated, wild-type $p 53$ protein binds to $p 53$ response elements residing around miR-34 gene promoter regions and promotes the transcription of miR-34. In GC cells, mutations in the p53 gene or genomic alterations of the $p 53$ binding site results in the downregulation of miR-34 expression. (B) DNA methylation of the miR-34 promoter regions. The regions surrounding the miR-34 gene promoter regions are widely embedded with CpG islands and spaced with nucleosomes. The DNA methyltransferase (DNMT) and histone deacetylase (HDAC) complexes are excluded from the promoter regions, and the miR-34 genes are normally expressed in normal cells. But in GC cells, the promoter regions of miR-34 genes are accessible to DNMT and HDAC complexes, causing the methylation of $\mathrm{CpG}$ islands and subsequent silencing of miR-34 genes transcription. Moreover, $H$. pylori infection is also associated with the methylation of miR-34, yet the concrete mechanism is unclear. (C) Histone modification of the miR-34 promoter regions. In GC cells, the histones of nucleosomes and lysine on histone $\mathrm{H} 3$ are methylated after methyl cytosine binding protein (MBP)- and HDAC-containing complexes bind to the promoter regions of miR-34 genes, causing transcriptional silencing of miR-34 genes. HOTAIR, HOX antisense intergenic RNA; PRC2, polycomb repressive complex 2; CA, co-activator protein; HAT, histone acetyltransferase; TF, transcription factor. (Modified from ref. 76).

on the above-mentioned studies, the putative mechanisms responsible for miR-34 gene silencing in GC, which include p53 mutations, DNA methylation, and histone modification, are partially described in Fig. 2.
In addition to the influence of the intrinsic factors described above, miRNA dysregulation by Helicobacter pylori (H. pylori) infection in gastric carcinogenesis has also been explored. H. pylori dysregulates the expression of 
various miRNAs in human gastric mucosa, which has been linked to $H$. pylori-induced host inflammatory immune responses and $H$. pylori-mediated gastric carcinogenesis (78). Chang et al reported that miR-34a was upregulated 2-fold in $H$. pylori-negative versus $H$. pylori-positive cancers (79). Suzuki et al demonstrated that the levels of miR-34b/c methylation were approximately three times higher in $H$. pylori-positive than $H$. pylori-negative mucosae (59), suggesting that methylation of $\mathrm{miR}-34 \mathrm{~b} / \mathrm{c}$ is associated with $H$. pylori infection. A more comprehensive understanding of the mechanisms underlying reduced expression of miR-34 is needed to fully explain miR-34 dysregulation by $H$. pylori. It is critically important to dissect these intricate pathways and to understand how host-pathogen interactions can disrupt these comprehensive regulatory pathways.

\section{Signalling pathways modulated by miR-34 in gastric cancer}

As a major downstream effector of receptor tyrosine kinases $(R T K s)$ and $\mathrm{G}$ protein-coupled receptors $(G P C R s)$, the phosphoinositide 3-kinase $(P I 3 K) / A K T$ pathway has been shown to play a crucial role in carcinogenesis and tumour development (80). Recent studies have revealed that nodes of the PI3K signal transduction system are frequently targeted by miRNAs in a variety of human cancers, including GC. Liu et al found that EGF-induced EGFR phosphorylation in GC cells activated $M M P-7$ and consequently promoted cancer invasion and metastasis, and this process could be inhibited by miR-34a via modulation of $P I 3 K / A K T$ signalling cascades (45). In addition, Peng et al found that miR-34a significantly decreased the phosphorylation of $A K T$ by targeting PDGFR and MET, two upstream RTKs. They also reported that miR-34a inhibited carcinogenesis, proliferation, invasion, and metastasis in GC by targeting PDGFR and MET through the PI3K/AKT pathway (48). Wang et al reported that miR-34a mimics plus diallyl disulphide (DADS) decreased the expression of phosphorylated $P I 3 K$ (p-PI3K) and phosphorylated $A K T$ (p-AKT), thereby causing inactivation of the $P I 3 K / A K T$ pathway and enhancing the anti-invasion and pro-apoptotic effects of DADS in SGC-7901 cells (81). The PI3K/AKT pathway has been demonstrated to be implicated in drug resistance in GC. Sun et al reported that the upregulation of survivin expression induced by $\mathrm{p}-\mathrm{AKT}$ and hypoxia-inducible factor $1 \alpha(H I F-1 \alpha)$ contributed to the cisplatin resistance of GC cells (82). Furthermore, Cao et al revealed that restoration of miR-34a improved the sensitivity of GC cells (SGC-7901) to cisplatin, possibly via the $P I 3 K / A K T /$ survivin signalling pathway (47).

In addition to the PI3K/AKT pathway, Tang et al used bioinformatic analysis to discover additional pathways that could be involved in the development and progression of GC and be modulated by miR-34a, including the $p 53$ signalling pathway, the mitogen-activated protein kinase $(M A P K)$, Wnt/ $\beta$-catenin, Smad, and Notch signalling pathways (83). Moreover, Liu et al reported that silencing of miR-34a induced by HOTAIR promoted EMT in GC, possibly through activation of the $H G F / c-M E T / S n a i l$ pathway (52). Kim et al demonstrated that in Epstein-Barr virus (EBV)-infected GC cells, transcriptional upregulation of NADPH oxidase
$2(N O X 2)$ and the subsequent accumulation of reactive oxygen species (ROS) was induced by EBV nuclear antigen 1 (EBNA1), through downregulation of miR34a expression (55). Together, these results suggest that EBNA1 promotes cell viability by regulating EBNA1/miR34a/NOX2/ROS signalling in GC cells (55).

\section{Clinical implications of miR-34}

Promising biomarkers in GC. The correlation between miR-34a expression and the prediction/prognosis for GC patients has been well established $(50,68,69)$. A higher recurrence rate and an inferior survival outcome have been observed in GC patients with low expression levels of miR-34a compared with patients who express higher miR-34a levels $(50,68)$. In addition to its value as a prognostic biomarker, the methylation level of miR-34 genes has also been explored in relation to the predictive merits for GC. Suzuki et al observed that the methylation level of miR-34b/c was higher in the gastric mucosa of patients with multiple GC than in the gastric mucosa of $H$. pylori-positive healthy controls or patients with single GC (59). In addition, the methylation level of miR-34b/c in noncancerous gastric body mucosa was an independent predictive risk factor for metachronous GC in patients treated with endoscopic submucosal dissection (ESD) (84). Therefore, frequent follow-up endoscopy is needed in GC patients presenting with high $\mathrm{miR}-34 \mathrm{~b} / \mathrm{c}$ methylation levels in the gastric body after ESD (84).

miR-34 polymorphism and GC risk. The most frequent genetic mutations in the human genome are single nucleotide polymorphisms (SNPs), which are variations of a single nucleotide. Since the regulatory function of miRNA is dependent on base complementation, a SNP occurring either in the miRNA seed regions or in targeted mRNA sequences may have significant effects (85-87). By in silico searching and database mining, Xu et al found a potentially functional common SNP rs4938723 (T>C) in the promoter region of pri-miR-34b/c (423-bp upstream from the transcription start site), which was located in a typical CpG island (88). Subsequently, Yang et al revealed that miR-34b/c rs4938723 CT/CC genotypes may be associated with a decreased risk of GC in a Chinese population and that the $\mathrm{C}$ allele may be a protective factor in GC (89). Pan et al demonstrated a lower occurrence rate of GC among patients with CT and CT/CC genotypes in miR-34b/c rs4938723 compared with patients with a TT genotype (90). These results were consistent with a meta-analysis study, which reported a reverse association between miR-34b/c rs4938723 polymorphism and susceptibility to GC (91).

Therapeutic applications in cancers. As a promising tumour suppressor, miR-34a has been considered as a therapeutic candidate in cancer. It is tempting to hypothesize that restoration of the expression of miR-34 may represent a novel and feasible treatment for GC patients, or that it could become a complementary therapy to conventional surgical resection and chemoradiation $(46,50,69)$. Consistent with its role as a negative regulator of CSCs in prostatic and pancreatic cancer, restoration of miR-34a has been documented to inhibit the self-renewal potential of gastric CSCs, which may offer a 
novel target against GC (10). The sensitivity to cisplatin could be restored to some extent by elevating cellular miR-34a, indicating that improved treatment could be obtained in GC patients by administering cisplatin together with miR-34a $(47,51)$. Moreover, ectopic expression of miR-34a can also elevate the sensitivity of GC cells with low levels of miR-34a expression to doxorubicin, gemcitabine, and docetaxel (10).

The development of immunotherapy targeting the PDI (programmed cell death protein 1) or $P D L 1$ (programmed death ligand 1) checkpoint has led to considerable progress in the treatment of many cancers. Recently, Wang et al showed that the downregulation of miR-34a in acute myeloid leukaemia was inversely correlated with high protein expression of $P D L 1$ and miR-34a was capable of targeting a predicted site in the PDL1 3'-UTR, resulting in transcriptional repression (92). Cortez et al also demonstrated that $p 53$ specifically modulated the tumour immune response in non-small cell lung cancer by repressing PDL1 via miR-34 (93). These results suggest that miR-34a could function as a potential immunotherapeutic target, and delivery of miR-34a combined with standard therapies may represent a new approach in cancer immunotherapy.

Although miR-34 overexpression has great therapeutic potential according to the recent research findings, a major challenge that limits the transition from basic in vitro studies to in vivo clinical applications is the deficiency of a miRNA delivery system that can elevate miR-34 in target sites to therapeutically optimal levels. It is significant that Jang et al has demonstrated that nano-vesicles containing poly-l-lysine-graft-imidazole (PLI)/miR-34a complexes (NVs/miR-34a) not only efficiently delivered miR-34a into GC cells in vitro but also successfully delivered miR-34a systemically with an accumulation of miR-34a by tumours in vivo (54). Significant antitumour efficacy was observed in a gastric tumour xenograft nude mouse model that was injected with NVs/miR-34a via the tail vein of the mouse (54). In addition, Di Martino et al described a lentiviral miR-34a mimic delivery system that elevated miR-34a expression significantly in multiple myeloma cells, and the multiple myeloma xenograft formation and size were suppressed by lentiviral miR-34a in the mouse models (94). Lentiviral delivery system was also used to deliver miR-34a to prostate cancer progenitor cells, and the results showed that the lentivirus-delivered miR-34a inhibited cancer cell metastasis (95). The stable nucleic acid lipid particle (SNALP) is a synthesized vector that provides another successful strategy for miR-34a mimic delivery, exhibiting high stability in serum but low toxicity. SNALP-encapsulated miR-34a mimics were successfully delivered in vitro in multiple myeloma (MM) cells with a significant change of gene expression with relevant effects on multiple signal transduction pathways (96). The same system was then experimented in vivo and the exciting results showed a significant inhibition of MM xenograft growth and a prolonged mice survival (96).

The application of miR-34a is not limited to laboratory, clinical trials have also confirmed the therapeutic prospect of miR-34a in various cancer types. Daige et al ever reported that the systemic delivery of MRX34, a liposome-formulated miR-34 mimic, increased the levels of miR34a expression by approximately 1,000-fold in vitro and caused the inhibition of liver tumour xenograft growth (97). Recently, MRX34 was included in clinical trials as the first miRNA-associated therapeutic agent. And the first clinical trial (NCT01829971) of MRX34 implemented in 2013 that enrolled 155 patients with 7 cancer types, including solid tumours and blood malignancies. In this trial a good therapeutic effect was observed but only with some immunoreaction, which provided bright prospect for MRX34 to clinical oncotherapy. In 2017, Beg et al recruited 47 patients with various solid tumours to assess the maximum tolerated dose (MTD), safety, pharmacokinetics, and clinical activity of MRX34. The authors found that MRX34 with dexamethasone premedication was associated with acceptable safety. And the MTD was $93 \mathrm{mg} / \mathrm{m}^{2}$ for hepatocellular carcinoma (HCC) patients and $110 \mathrm{mg} / \mathrm{m}^{2}$ for non-HCC patients (98).

\section{Conclusion}

The three miR-34 isoforms (i.e. miR-34a and miR-34b/c) are encoded by two different transcriptional units. Furthermore, the seed sequence of miR-34a and miR-34c is identical, indicating that they hold similar mRNA targets, while miR-34b is a little different, as described in Fig. 1 and Table I. miR-34a and $\mathrm{miR}-34 \mathrm{~b} / \mathrm{c}$ are direct target genes of $p 53$ which has been shown to be downregulated or lost in various types of malignancies, including gastric cancer (GC) (Table III and Table IV). Moreover, it has been demonstrated to play a crucial role in repressing tumorigenesis and progression. This tumour-suppressive process is credited to the regulation of multiple biological processes, including cell cycle arrest, metastasis, induction of senescence and apoptosis by targeting more than 30 different oncogenes (e.g. SIRT1, $Y Y 1$, MMP7, PDGFR- $\alpha / \beta$, Met, Bcl-2, Snail, Tgif2, HMGA2, CD44, $N O X 2$ and IGF2BP3), as well as tumour immune evasion by targeting $P D-L 1$, death-associated protein kinase 2 (DAPK2), specificity protein $1(S p l)$ or androgen receptor $(A R)(99,100)$. Moreover, miR-34a and miR-34b/c have been demonstrated to target the expression of the same oncogenes such as $Y Y 1$, Bcl-2, Notch and HMGA2 in gastric cancer to regulate cancer metastasis, stemness and apoptosis (Table II). Several key mediators or signalling pathway nodes (e.g. PI3K/AKT, $M A P K$, Wnt/ $\beta$-catenin, Smad and Notch pathways) that are abnormally activated during the process of carcinogenesis have been shown to be effectively modulated by miR-34 in GC. A large number of studies concerning the use of miR-34a mimics for cancer therapy have been carried out in vitro and in vivo, and its tumour suppressive role has been confirmed. Many vectors such as nanovesicles, lentiviruses, SNALPs, polymeric nanogels and liposomes have been designed to achieve the effective systemic delivery of miR-34a mimics. The application of miR-34a in clinical oncotherapy has also been mentioned. MRX34, a liposome-formulated miR-34 mimic, serving as the first miRNA-associated drug for oncotherapy tested in clinical trials, exhibited good antitumor activity in patients with refractory solid tumours and blood malignancies. Moreover, the application of MRX34 for treating numerous types of cancers is feasible, contributing to its broad distribution in various tissues $(97,98)$. The combinations of miR-34a with other tumour-suppressive miRNA agents in 'cocktails', such as in combination with miR-15a, may benefit patients by means of the synergistic effects. Moreover, when administered 
together, miR-34a can elevate the sensitivity of cancer cells to chemotherapeutic agents, including cisplatin, gemcitabine and docetaxel. Additionally, miR-34a and miR-34b/c have also been demonstrated to play a significant role in tumour suppression in vitro. However, few studies of $\mathrm{miR}-34 \mathrm{~b} / \mathrm{c}$ in vivo have been reported, thus their application for oncotherapy in the clinic warrants exploration.

In conclusion, miR-34 has been identified as a novel diagnostic, prognostic, and predictive biomarker for GC, and restoration of miR-34 levels may produce a synergistic effect with other drugs to achieve a better clinical outcome in GC patients.

\section{Acknowledgements}

The authors wish to thank the reviewers for the valuable suggestions that significantly improved the quality of this manuscript.

\section{Funding}

The present study was funded by grants from the National Science Foundation of China (nos. 81160307 and 81560395).

\section{Availability of data and materials}

Not applicable.

\section{Authors' contributions}

SX and MH wrote the manuscript. SX constructed the tables and diagrams. SX, MH, CL, HC and XZ checked and revised the manuscript. SX, MH, HC and XZ were responsible for the submission of this manuscript and final approval of the version to be published. All the authors were also involved in the conception and design of the study, as well as the acquisition, analysis and interpretation of data for the work. All authors agree to be accountable for all aspects of the research in ensuring that the accuracy or integrity of any part of the work are appropriately investigated and resolved.

\section{Ethics approval and consent to participate}

Not applicable.

\section{Patient consent for publication}

Not applicable.

\section{Competing interests}

The authors have declared that there are no conflicts of interest.

\section{References}

1. Torre LA, Bray F, Siegel RL, Ferlay J, Lortet-Tieulent J and Jemal A Global cancer statistics, 2012. CA Cancer J Clin 65: 87-108, 2015.

2. Plummer M, Franceschi S, Vignat J, Forman D and Martel C: Global burden of gastric cancer attributable to Helicobacter pylori. Int J Cancer 136: 487-490, 2015.

3. Tsugane $\mathrm{S}$ and Sasazuki S: Diet and the risk of gastric cancer: Review of epidemiological evidence. Gastric Cancer 10: 75-83, 2007.
4. Bartel DP: MicroRNAs: Target recognition and regulatory functions. Cell 136: 215-233, 2009.

5. Pasquinelli AE: MicroRNAs and their targets: Recognition, regulation and an emerging reciprocal relationship. Nat Rev Genet 13: 271-282, 2012.

6. Hayes J, Peruzzi PP and Lawler S: MicroRNAs in cancer: Biomarkers, functions and therapy. Trends Mol Med 20: 460-469, 2014.

7. Bommer GT, Gerin I, Feng Y, Kaczorowski AJ, Kuick R, Love RE, Zhai Y, Giordano TJ, Qin ZS, Moore BB, et al: p53-mediated activation of miRNA34 candidate tumor-suppressor genes. Curr Biol 17: 1298-1307, 2007.

8. Dingli D and Michor F: Successful therapy must eradicate cancer stem cells. Stem Cells 24: 2603-2610, 2006.

9. Dontu G, Al-Hajj M, Abdallah WM, Clarke MF and Wicha MS: Stem cells in normal breast development and breast cancer. Cell Prolif 36 (Suppl 1): S59-S72, 2003.

10. Ji Q, Hao X, Meng Y, Zhang M, Desano J, Fan D and Xu L: Restoration of tumor suppressor miR-34 inhibits human p53-mutant gastric cancer tumorspheres. BMC Cancer 8: 266, 2008.

11. Versteeg R, Caron H, Cheng NC, van der Drift P, Slater R, Westerveld A, Voûte PA, Delattre O, Laureys G, Van Roy N, et al: 1p36: every subband a suppressor? Eur J Cancer 31A: 538-541, 1995.

12. Rodriguez A, Griffiths-Jones S, Ashurst JL and Bradley A: Identification of mammalian microRNA host genes and transcription units. Genome Res 14: 1902-1910, 2004.

13. He L, He X, Lim LP, de Stanchina E, Xuan Z, Liang Y, Xue W, Zender L, Magnus J, Ridzon D, et al: A microRNA component of the p53 tumour suppressor network. Nature 447: 1130-1134, 2007.

14. Ha M and Kim VN: Regulation of microRNA biogenesis. Nat Rev Mol Cell Biol 15: 509-524, 2014.

15. Krawetz SA, Kruger A, Lalancette C, Tagett R, Anton E, Draghici S and Diamond MP: A survey of small RNAs in human sperm. Hum Reprod 26: 3401-3412, 2011.

16. Jafari $\mathrm{N}$ and Abediankenari S: MicroRNA-34 dysregulation in gastric cancer and gastric cancer stem cell. Tumour Biol 39: $1010428317701652,2017$.

17. Vogelstein B, Lane D and Levine AJ: Surfing the p53 network. Nature 408: 307-310, 2000.

18. Riley T, Sontag E, Chen P and Levine A: Transcriptional control of human p53-regulated genes. Nat Rev Mol Cell Biol 9: 402-412, 2008.

19. Tarasov V, Jung P, Verdoodt B, Lodygin D, Epanchintsev A, Menssen A, Meister G and Hermeking H: Differential regulation of microRNAs by $\mathrm{p} 53$ revealed by massively parallel sequencing: miR-34a is a p53 target that induces apoptosis and G1-arrest. Cell Cycle 6: 1586-1593, 2007.

20. Chang TC, Wentzel EA, Kent OA, Ramachandran K, Mullendore M, Lee KH, Feldmann G, Yamakuchi M, Ferlito M, Lowenstein CJ, et al: Transactivation of miR-34a by p53 broadly influences gene expression and promotes apoptosis. Mol Cell 26: 745-752, 2007.

21. Yamakuchi M, Ferlito $M$ and Lowenstein CJ: miR-34a repression of SIRT1 regulates apoptosis. Proc Natl Acad Sci USA 105: 13421-13426, 2008.

22. Menssen A, Hydbring P, Kapelle K, Vervoorts J, Diebold J, Lüscher B, Larsson LG and Hermeking H: The c-MYC oncoprotein, the NAMPT enzyme, the SIRT1-inhibitor DBC1, and the SIRT1 deacetylase form a positive feedback loop. Proc Natl Acad Sci USA 109: E187-E196, 2012.

23. Mandke P, Wyatt N, Fraser J, Bates B, Berberich SJ and Markey MP: MicroRNA-34a modulates MDM4 expression via a target site in the open reading frame. PLoS One 7: e42034, 2012.

24. Christoffersen NR, Shalgi R, Frankel LB, Leucci E, Lees M, Klausen M, Pilpel Y, Nielsen FC, Oren M and Lund AH: p53-independent upregulation of miR-34a during oncogene-induced senescence represses MYC. Cell Death Differ 17: 236-245, 2010.

25. Welch C, Chen Y and Stallings RL: MicroRNA-34a functions as a potential tumor suppressor by inducing apoptosis in neuroblastoma cells. Oncogene 26: 5017-5022, 2007.

26. Raver-Shapira N, Marciano E, Meiri E, Spector Y, Rosenfeld N, Moskovits N, Bentwich Z and Oren M: Transcriptional activation of miR-34a contributes to p53-mediated apoptosis. Mol Cell 26: 731-743, 2007.

27. Rokavec M, Li H, Jiang L and Hermeking H: The p53/miR-34 axis in development and disease. J Mol Cell Biol 6: 214-230, 2014. 
28. Sun F, Fu H, Liu Q, Tie Y, Zhu J, Xing R, Sun Z and Zheng X: Downregulation of CCND1 and CDK6 by miR-34a induces cell cycle arrest. FEBS Lett 582: 1564-1568, 2008.

29. Mudduluru G, Ceppi P, Kumarswamy R, Scagliotti GV, Papotti M and Allgayer H: Regulation of Axl receptor tyrosine kinase expression by miR-34a and miR-199a/b in solid cancer. Oncogene 30: 2888-2899, 2011.

30. Wang B, Li D, Kovalchuk I, Apel IJ, Chinnaiyan AM, Wóycicki RK, Cantor CR and Kovalchuk O: miR-34a directly targets tRNAiMet precursors and affects cellular proliferation, cell cycle, and apoptosis. Proc Natl Acad Sci USA 115: 7392-7397, 2018.

31. Grammatikakis I, Gorospe M and Abdelmohsen K: Modulation of cancer traits by tumor suppressor microRNAs. Int J Mol Sci 14: 1822-1842, 2013.

32. Zhou Y, Huang T, Siu HL, Wong CC, Dong Y, Wu F, Zhang B, Wu WK, Cheng AS, Yu J, et al: IGF2BP3 functions as a potential oncogene and is a crucial target of miR-34a in gastric carcinogenesis. Mol Cancer 16: 77, 2017.

33. Wang AM, Huang TT, Hsu KW, Huang KH, Fang WL, Yang MH, Lo SS, Chi CW, Lin JJ and Yeh TS: Yin Yang 1 is a target of microRNA-34 family and contributes to gastric carcinogenesis Oncotarget 5: 5002-5016, 2014.

34. Mert U, Ozgür E, Tiryakioglu D, Dalay N and Gezer U: Induction of p53-inducible microRNA miR-34 by gamma radiation and bleomycin are different. Front Genet 3: 220, 2012.

35. Polyak K, Xia Y, Zweier JL, Kinzler KW and Vogelstein B: A model for p53-induced apoptosis. Nature 389: 300-305, 1997.

36. Shen Z, Zhan G, Ye D, Ren Y, Cheng L, Wu Z and Guo J: MicroRNA-34a affects the occurrence of laryngeal squamous cell carcinoma by targeting the antiapoptotic gene survivin. Med Oncol 29: 2473-2480, 2012.

37. Deng X, Zheng H, Li D, Xue Y, Wang Q, Yan S, Zhu Y and Deng M: MicroRNA-34a regulates proliferation and apoptosis of gastric cancer cells by targeting silent information regulator 1 . Exp Ther Med 15: 3705-3714, 2018.

38. Lin L, Jiang H, Huang M, Hou X, Sun $X$, Jiang $X$, Dong $X$, Sun X, Zhou B and Qiao H: Depletion of histone deacetylase 1 inhibits metastatic abilities of gastric cancer cells by regulating the miR-34a/CD44 pathway. Oncol Rep 34: 663-672, 2015.

39. Ha SY, Lee J, Kang SY, Do IG, Ahn S, Park JO, Kang WK Choi MG, Sohn TS, Bae JM, et al: MET overexpression assessed by new interpretation method predicts gene amplification and poor survival in advanced gastric carcinomas. Mod Pathol 26 . 1632-1641, 2013

40. Takaishi S, Okumura T, Tu S, Wang SS, Shibata W, Vigneshwaran R, Gordon SA, Shimada Y and Wang TC: Identification of gastric cancer stem cells using the cell surface marker CD44. Stem Cells 27: 1006-1020, 2009.

41. $\mathrm{Pu} \mathrm{Y}$, Zhao F, Wang $\mathrm{H}$ and Cai S: miR-34a-5p promotes multi-chemoresistance of osteosarcoma through down-regulation of the DLL1 gene. Sci Rep 7: 44218, 2017.

42. Krause CJ, Popp O, Thirunarayanan N, Dittmar G, Lipp M and Müller G: MicroRNA-34a promotes genomic instability by a broad suppression of genome maintenance mechanisms downstream of the oncogene KSHV-vGPCR. Oncotarget 7 : 10414-10432, 2016.

43. Dutta KK, Zhong Y, Liu YT, Yamada T, Akatsuka S, Hu Q, Yoshihara M, Ohara H, Takehashi M, Shinohara T, et al: Association of microRNA-34a overexpression with proliferation is cell type-dependent. Cancer Sci 98: 1845-1852, 2007.

44. Hao Q, Lu X, Liu N, Xue X, Li M, Zhang C, Qin X, Li W, Shu Z, Song B, et al: Posttranscriptional deregulation of Src due to aberrant miR34a and miR203 contributes to gastric cancer development. BMB Rep 46: 316-321, 2013.

45. Liu G, Jiang C, Li D, Wang R and Wang W: miRNA-34a inhibits EGFR-signaling-dependent MMP7 activation in gastric cancer. Tumour Biol 35: 9801-9806, 2014

46. Cao W, Fan R, Wang L, Cheng S, Li H, Jiang J, Geng M, Jin Y and Wu Y: Expression and regulatory function of miRNA-34a in targeting survivin in gastric cancer cells. Tumor Biol 34: 963-971, 2013

47. Cao W, Yang W, Fan R, Li H, Jiang J, Geng M, Jin Y and Wu Y: miR-34a regulates cisplatin-induce gastric cancer cell death by modulating PI3K/AKT/survivin pathway. Tumour Biol 35 $1287-1295,2014$

48. Peng Y, Guo JJ, Liu YM and Wu XL: MicroRNA-34A inhibits the growth, invasion and metastasis of gastric cancer by targeting PDGFR and MET expression. Biosci Rep 34: pii: e00112, 2014.
49. He M, Gao L, Zhang S, Tao L, Wang J, Yang J and Zhu M: Prognostic significance of miR-34a and its target proteins of FOXP1, p53, and BCL2 in gastric MALT lymphoma and DLBCL. Gastric Cancer 17: 431-441, 2014.

50. Wei B, Huang QY, Huang SR, Mai W and Zhong XG MicroRNA-34a attenuates the proliferation, invasion and metastasis of gastric cancer cells via downregulation of MET. Mol Med Rep 12: 5255-5261, 2015.

51. Zhang Z, Kong Y, Yang W, Ma F, Zhang Y, Ji S, Ma EM, Liu H, Chen Y and Hua Y: Upregulation of microRNA-34a enhances the DDP sensitivity of gastric cancer cells by modulating proliferation and apoptosis via targeting MET. Oncol Rep 36: 2391-2397, 2016.

52. Liu YW, Sun M, Xia R, Zhang EB, Liu XH, Zhang ZH, Xu TP, De W, Liu BR and Wang ZX: LincHOTAIR epigenetically silences miR34a by binding to PRC2 to promote the epithelial-to-mesenchymal transition in human gastric cancer. Cell Death 6: e1802, 2015

53. $\mathrm{Hu} \mathrm{Y,} \mathrm{Pu} \mathrm{Q,} \mathrm{Cui} \mathrm{B} \mathrm{and} \mathrm{Lin} \mathrm{J:} \mathrm{MicroRNA-34a} \mathrm{inhibits} \mathrm{tumor}$ invasion and metastasis in gastric cancer by targeting Tgif2. Int $J$ Clin Exp Pathol 8: 8921-8928, 2015.

54. Jang E, Kim E, Son HY, Lim EK, Lee H, Choi Y, Park K, Han S, Suh JS, Huh YM and Haam S: Nanovesicle-mediated systemic delivery of microRNA-34a for CD44 overexpressing gastric cancer stem cell therapy. Biomaterials 105: 12-24, 2016.

55. Kim S-M, Hur DY, Hong SW and Kim JH: EBV-encoded EBNA1 regulates cell viability by modulating miR34a-NOX2-ROS signaling in gastric cancer cells. Biochem Biophys Res Commun 494: 550-555, 2017.

56. Bader AG: miR-34-a microRNA replacement therapy is headed to the clinic. Front Genet 3: 120, 2012.

57. Hui WT, Ma XB, Zan Y, Wang XJ and Dong L: Prognostic significance of miR-34a expression in patients with gastric cancer after radical gastrectomy. Chin Med J (Engl) 128: 2632-2637, 2015.

58. Kim CH, Kim HK, Rettig RL, Kim J, Lee ET, Aprelikova O, Choi IJ, Munroe DJ and Green JE: miRNA signature associated with outcome of gastric cancer patients following chemotherapy. BMC Med Genomics 4: 79, 2011.

59. Suzuki H, Yamamoto E, Nojima M, Kai M, Yamano HO Yoshikawa K, Kimura T, Kudo T, Harada E, Sugai T, et al: Methylation-associated silencing of microRNA-34b/c in gastric cancer and its involvement in an epigenetic field defect. Carcinogenesis 31: 2066-2073, 2010.

60. Stánitz E, Juhász K, Tóth C, Gombos K, Natali PG and Ember I: Evaluation of MicroRNA expression pattern of gastric adenocarcinoma associated with socioeconomic, environmental and lifestyle factors in northwestern Hungary. Anticancer Res 33: 3195-3200, 2013

61. Katada T, Ishiguro H, Kuwabara Y, Kimura M, Mitui A, Mori Y, Ogawa R, Harata K and Fujii Y: microRNA expression profile in undifferentiated gastric cancer. Int J Oncol 34: 537-542, 2009

62. Yao Y, Suo AL, Li ZF, Liu LY, Tian T, Ni L, Zhang WG, Nan KJ, Song TS and Huang C: MicroRNA profiling of human gastric cancer. Mol Med Rep 2: 963-970, 2009.

63. Osawa S, Shimada Y, Sekine S, Okumura T, Nagata T, Fukuoka J and Tsukada K: MicroRNA profiling of gastric cancer patients from formalin-fixed paraffin-embedded samples. Oncol Lett 2: 613-619, 2011.

64. Su Y, Ni Z, Wang G, Cui J, Wei C, Wang J, Yang Q, Xu Y and $\mathrm{Li} F$ : Aberrant expression of microRNAs in gastric cancer and biological significance of miR-574-3p. Int Immunopharmacol 13: 468-475, 2012

65. Tsukamoto Y, Nakada C, Noguchi T, Tanigawa M, Nguyen LT, Uchida T, Hijiya N, Matsuura K, Fujioka T, Seto M and Moriyama M: MicroRNA-375 is downregulated in gastric carcinomas and regulates cell survival by targeting PDK1 and 14-3-3zeta. Cancer Res 70: 2339-2349, 2010.

66. Tsai KW, Wu CW, Hu LY, Li SC, Liao YL, Lai CH, Kao HW, Fang WL, Huang KH, Chan WC and Lin WC: Epigenetic regulation of miR-34b and miR-129 expression in gastric cancer. Int J Cancer 129: 2600-2610, 2011

67. Liu D, Hu X, Zhou H, Shi G and Wu J: Identification of aberrantly expressed miRNAs in gastric cancer. Gastroenterol Res Pract 2014: 473817, 2014.

68. Zhang H, Li S, Yang J, Liu S, Gong X and Yu X: The prognostic value of miR-34a expression in completely resected gastric cancer: Tumor recurrence and overall survival. Int J Clin Exp Med 8: 2635-2641, 2015. 
69. Yang B, Huang J, Liu H, Guo W and Li G: miR-335 directly, while miR-34a indirectly modulate survivin expression and regulate growth, apoptosis, and invasion of gastric cancer cells. Tumour Biol 37: 1771-1779, 2016.

70. Wang L, Yu J, Xu J, Zheng C, Li X and Du J: The analysis of microRNA-34 family expression in human cancer studies comparing cancer tissues with corresponding pericarcinous tissues. Gene 554: 1-8, 2015.

71. Hanazono K, Natsugoe S, Stein HJ, Aikou T, Hoefler H and Siewert JR: Distribution of p53 mutations in esophageal and gastric carcinomas and the relationship with p53 expression. Oncol Rep 15: 821-824, 2006.

72. Corney DC, Hwang CI, Matoso A, Vogt M, Flesken-Nikitin A, Godwin AK, Kamat AA, Sood AK, Ellenson LH, Hermeking H and Nikitin AYFrequent downregulation of miR-34 family in human ovarian cancers. Clin Cancer Res 16: 1119-1128, 2010.

73. Lodygin D, Tarasov V, Epanchintsev A, Berking C, Knyazeva T, Körner H, Knyazev P, Diebold J and Hermeking H: Inactivation of miR-34a by aberrant $\mathrm{CpG}$ methylation in multiple types of cancer. Cell Cycle 7: 2591-2600, 2008.

74. Gal-Yam EN, Saito Y, Egger G and Jones PA: Cancer epigenetics: Modifications, screening, and therapy. Annu Rev Med 59: 267-280, 2008

75. Jones PA and Baylin SB: The fundamental role of epigenetic events in cancer. Nat Rev Genet 3: 415-428, 2002.

76. Hermeking H: The miR-34 family in cancer and apoptosis. Cell Death Differ 17: 193-199, 2010.

77. Zhang S, Chen P, Huang Z, Hu X, Chen M, Hu S, Hu Y and Cai T: Sirt7 promotes gastric cancer growth and inhibits apoptosis by epigenetically inhibiting miR-34a. Sci Rep 5: 9787, 2015

78. Noto JM and Peek RM: The role of microRNAs in Helicobacter pylori pathogenesis and gastric carcinogenesis. Front Cell Infect Microbiol 1: 21, 2012.

79. Chang H, Kim N, Park JH, Nam RH, Choi YJ, Lee HS, Yoon H, Shin CM, Park YS, Kim JM and Lee DH: Different microRNA expression levels in gastric cancer depending on Helicobacter pylori infection. Gut Liver 9: 188-196, 2015.

80. Liu P, Cheng H, Roberts TM and Zhao JJ: Targeting the phosphoinositide 3-kinase pathway in cancer. Nat Rev Drug Discov 8: 627-644, 2009.

81. Wang G, Liu G, Ye Y, Fu Y and Zhang X: Upregulation of miR-34a by diallyl disulfide suppresses invasion and induces apoptosis in SGC-7901 cells through inhibition of the PI3K/Akt signaling pathway. Oncol Lett 11: 2661-2667, 2016.

82. Sun XP, Dong X, Lin L, Jiang X, Wei Z, Zhai B, Sun B, Zhang Q, Wang $\mathrm{X}$, Jiang $\mathrm{H}$, et al: Up-regulation of survivin by AKT and hypoxia-inducible factor $1 \alpha$ contributes to cisplatin resistance in gastric cancer. FEBS J 281: 115-128, 2014.

83. Tang T, Su R, Wang B and Zhang Y: An integrated approach of predicted miR-34a targets identifies a signature for gastric cancer. Oncol Lett 10: 653-660, 2015.

84. Suzuki R, Yamamoto E, Nojima M, Maruyama R, Yamano HO, Yoshikawa K, Kimura T, Harada T, Ashida M, Niinuma T, et al: Aberrant methylation of microRNA-34b/c is a predictive marker of metachronous gastric cancer risk. J Gastroenterol 49: 1135-1144, 2014.

85. Saunders MA, Liang H and Li WH: Human polymorphism at microRNAs and microRNA target sites. Proc Natl Acad Sci USA 104: 3300-3305, 2007

86. Cai M, Zhang Y, Ma Y, Li W, Min P, Qiu J, Xu W, Zhang M, Li M, Li L, et al: Association between microRNA-499 polymorphism and gastric cancer risk in Chinese population. Bull Cancer 102: 973-978, 2015
87. Jiang J, Jia ZF, Cao DH, Wu YH, Sun ZW and Cao XY: Association of the miR-146a rs2910164 polymorphism with gastric cancer susceptibility and prognosis. Future Oncol 12: 2215-2226, 2016

88. Xu Y, Liu L, Liu J, Zhang Y, Zhu J, Chen J, Liu S, Liu Z, Shi H, Shen $\mathrm{H}$ and $\mathrm{Hu} \mathrm{Z}$ : A potentially functional polymorphism in the promoter region of $\mathrm{miR}-34 \mathrm{~b} / \mathrm{c}$ is associated with an increased risk for primary hepatocellular carcinoma. Int J Cancer 128: 412-417, 2011.

89. Yang C, Ma X, Liu D, Wang Y, Tang R, Zhu Y, Xu Z and Yang L: Promoter polymorphisms of miR-34b/c are associated with risk of gastric cancer in a Chinese population. Tumour Biol 35: 12545-12554, 2014

90. Pan XM, Sun RF, Li ZH, Guo XM, Qin HJ and Gao LB: Pri-miR-34b/c rs4938723 polymorphism is associated with a decreased risk of gastric cancer. Genet Test Mol Biomarkers 19: 198-202, 2015

91. Li H, Diao S, Li J, Ma B and Yuan S: An updated meta-analysis of 23 case-control studies on the association between miR-34b/c polymorphism and cancer risk. Oncotarget 8: 28888-28896, 2017.

92. Wang X, Li J, Dong K, Lin F, Long M, Ouyang Y, Wei J, Chen X, Weng Y, He T and Zhang H: Tumor suppressor miR-34a targets PD-L1 and functions as a potential immunotherapeutic target in acute myeloid leukemia. Cell Signal 27: 443-452, 2015.

93. Cortez MA, Ivan C, Valdecanas D, Wang X, Peltier HJ, Ye Y, Araujo L, Carbone DP, Shilo K, Giri DK, et al: PDL1 Regulation by p53 via miR-34. J Natl Cancer Inst 108: pii: djv303, 2015.

94. Di Martino MT, Leone E, Amodio N, Foresta U, Lionetti M, Pitari MR, Cantafio ME, Gullà A, Conforti F, Morelli E, et al: Synthetic miR-34a mimics as a novel therapeutic agent for multiple myeloma: In vitro and in vivo evidence. Clin Cancer Res 18: 6260-6270, 2012

95. Liu C, Kelnar K, Liu B, Chen X, Calhoun-Davis T, Li H, Patrawala L, Yan H, Jeter C, Honorio S, et al: The microRNA miR-34a inhibits prostate cancer stem cells and metastasis by directly repressing CD44. Nat Med 17: 211-215, 2011.

96. Di Martino MT, Campani V, Misso G, Gallo Cantafio ME, Gullà A, Foresta U, Guzzi PH, Castellano M, Grimaldi A, Gigantino $\mathrm{V}$, et al: In vivo activity of miR-34a mimics delivered by stable nucleic acid lipid particles (SNALPs) against multiple myeloma. PLoS One 9: e90005, 2014

97. Daige CL, Wiggins JF, Priddy L, Nelligan-Davis T, Zhao J and Brown D: Systemic delivery of a miR34a mimic as a potential therapeutic for liver cancer. Mol Cancer Ther 13: 2352-2360, 2014.

98. Beg MS, Brenner AJ, Sachdev J, Borad M, Kang YK, Stoudemire J, Smith S, Bader AG, Kim S and Hong DS: Phase I study of MRX34, a liposomal miR-34a mimic, administered twice weekly in patients with advanced solid tumors. Invest New Drugs 35: 180-188, 2017.

99. Shi L, Lin H, Li G, Sun Y, Shen J, Xu J, Lin C, Yeh S, Cai X and Chang C: Cisplatin enhances NK cells immunotherapy efficacy to suppress HCC progression via altering the androgen receptor (AR)-ULBP2 signals. Cancer Lett 373: 45-56, 2016

100. Yan LH, Chen ZN, Li L, Chen J, Mo XW, Qin YZ, Wei WE, Qin HQ, Lin Y and Chen JS: E2F-1 promotes DAPK2-induced anti-tumor immunity of gastric cancer cells by targeting miR-34a. Tumor Biol, Oct 4, 2016 (Epub ahead of print). 